\title{
Removal of Biochemical and Chemical Oxygen Demands in Vegetable Oil Industry Effluents using Adsorbents from Fluted Pumpkin Mesocarp
}

\author{
Verla Andrew Wirnkor" \\ Group Research in Analytical Chemistry, Environment and Climate Change (GRACE \& CC), Department of \\ Chemistry, Faculty of Science, Imo State University Owerri, Imo State, Nigeria.
}

*Corresponding Author: Verla Andrew Wirnkor Group Research in Analytical Chemistry, Environment and Climate Change (GRACE \& CC), Department of Chemistry, Faculty of Science, Imo State University Owerri, Imo State, Nigeria.

\begin{abstract}
Isotherm, kinetic and thermodynamic studies could generate vital information for the design of sorption systems in treating industrial effluents. In the present study equilibrium adsorption data collected from batch experiments were fitted into isotherms, kinetics and thermodynamics models. Results reveal that best fit of adsorption followed the order; Temkin > Freundlich > Langmuir >Dubinin-Raduschkevich isotherm models. The BOD and COD adsorption increased with increasing contact time and the adsorption rate constant $(\mathrm{kad})$ followed the pseudo-second order kinetics.Kinetic parameters showed that adsorption was best described by pseudo-first order kinetic model. Gibbs free energy ( $\Delta G o)$ changes were positive, the enthalpy $(\triangle H o)$ changes were positive and the entropy ( $\triangle \mathrm{So}$ ) changes of sorption were negative. These thermodynamic parameters reveal that the endothermic non-spontaneous adsorption processes were feasible, though requiring chemisorptions. Therefore physically prepared adsorbents from fluted pumpkin mesocarp can be used in adsorption systems for reducing BOD and COD of vegetable oil industry effluents.
\end{abstract}

Keywords: Adsorption, Activated carbon, Isotherm, Kinetics, Thermodynamics

\section{INTRODUCTION}

Explanation modeling is the concept of fitting pollutant concentration data from experimental data into model equation. This elicits estimates of useful information such as isotherms, kinetics and thermodynamics parameters (Horsfall and spiff 2005; Maduagwu, 2008; Ekpete et al., 2010) that ordinarily are not obtained directly from original data in the specific system (Dunnivant and Anders, 2006). Such information is vital for the design and operating conditions of both batch and column sorption systems.

Effluents from vegetable oil industry have been shown to contain substantial amounts of dissolved organic pollutants. These effluents readily deteriorate the quality of receiving of land, water body and air to which they are disposed as a result of non-biodegradable (Arbike, 2000) and sometimes volatile nature of these organic pollutants. Therefore conventional waste water treatment methods have become increasingly insufficient to the ever increasing environmental quality standards. Although physicochemical treatment processes like ultra-filtration, precipitation; biological methods and adsorption technology is considered to be the most effective, Frusta and Aly, 1987 argued that adsorption technology has wide application in both water and waste treatment due to its multifunctional nature.

Activated carbon is a black microcrystalline carbonaceous material with high porosity; large available surface area and different functional groups on its surface (Verla, et al., 2012a). Activated carbon adsorption is an extremely versatile technology. For many water treatment applications adsorption has proven to be the least expensive treatment option. Adsorption is particularly effective in treating low concentration waste streams and in meeting stringent treatment levels. One of the major attributes of activated carbon treatment is its ability to remove a wide variety of toxic organic compounds to nondetectable levels. Its suitability on a specific application will normally depend on costs as they relate to the amount of carbon consumed. 
Yeh and Thomas, 1995 showed that removal of organic pollutants from industrial waste stream by adsorption unit using granular $\mathrm{AC}$ in fixed beds is an important industrial wastewater treatment. Baker at el., 1973 used AC to remove highly odorous dissolved organic compounds from industrial waste. Mohammed et al., 2005 studied phenol adsorption trend using locally produced AC form date palm pits. Anuda and Ibrahim, (2006) compared adsorption efficiency of coconut shell-based AC with efficiency of commercial carbon. Isotherms were used to evaluate the adsorption process and results showed that chemical oxygen demand (COD) was highly reduced in the coconut shell-based carbon than commercial carbon. Ademiluyi et al., 2009 studied the adsorption and treatment of organic pollutants using activated carbon from waste Nigerian bambo and noted that organic pollutant concentration expressed as COD was reduced to favorable refinery effluents specification. Ekpete et al., (2010) investigated the potential of fluted and commercial activated carbons for phenol removal in aqueous systems. Equilibrium adsorption data fitted well to mathematical models, confirming that good quality activated carbon could be produced from fluted pumpkin (Telfairia, occidentalis Hook. F.)stem wastes for removal of phenol studies from aqueous media.

Liquid phase adsorption isotherms have been developed for most commercial activated carbons for a variety of specific compounds with time dependence of sorption measured in terms of concentrations of single standard solutions analyzed using the pseudo-first and second order models (Ho et al., 1995, Njoku et al., 2014, Isuiku et al., 2016).

In the present study adsorption treatment of vegetable oil industry effluents in which organic pollutants are expressed as biochemical oxygen demand (BOD) and chemical oxygen demand (COD). However many authors have demonstrated the production of quality AC from agro waste. In continuation of research on the concept of reduce, recycle and reuse of waste, fluted pumpkin shellbased waste activated carbon was prepared elsewhere, and used to examine the adsorption of organic pollutants in vegetable oil industry effluent. Usable water could be obtained from such an adsorption treatment. Data from this study could enhance understanding of the interaction of organic pollutants in vegetable oil industry effluents thereby forming the bases for controlling them in an economically acceptable and environmentally safe manner.

\section{Material AND MethodS}

\subsection{BATCH ADSORPTION EXPERIMENT ON REMOVAL OF BOD AND COD}

Batch and column adsorption studies were performed to evaluate the influence of various experimental parameters such as $\mathrm{pH}$,contact time, temperature and carbon dose on removal of BOD and COD of VOIE. Activated carbon samples were sieved through $300 \mu \mathrm{m}$ mesh size and preliminary experiments showed that $106 \mu \mathrm{m}-300 \mu \mathrm{m}$ mesh size packed into a glass column on a glass wool support. VOIE was allowed to transit through the bed under gravity. There was continuous flow while there was impended flow for mesh size below 200 $\mu \mathrm{m}$. (Mensha et al., 2008 and Nawa and Doma, 1989).

\subsection{BOD AND COD VARIATION WITH CONTACT TIME}

$50 \mathrm{mls}$ of VOIE of BODi and CODi were taken into five conical flasks and $1 \mathrm{~g}$ of various PFAC was added and agitated at various time periods of 1, 2, 3, 4, 5 and $6 \mathrm{hrs}$ respectively. The solutions were filtered through Whatman No 41, then centrifuged at 1000rpm for 5mins, decanted and their BODs and CODs read off with use of a digital BOD manometer model.

\subsection{BOD AND COD VARIATION WITH CARBON DOSE}

This was carried out according to Higachi and Oishi, (1984) with modifications. Briefly, various mass of PFAC in grams from 0.5, 1, 1.5, 2, 2.5 and 3g were weighed and transferred into $250 \mathrm{mls}$ conical flask. VOIE of BODi and COD i were placed into the conical flask. The flask were tightly stopped with aluminium foil and agitated for $1 \mathrm{hr}$ by centrifugation at $1000 \mathrm{rpm}$ for $5 \mathrm{mins}$, allowed to settle, decanted and filtered with What man number 41. The BOD and COD of filtered sample were measured. This procedure was repeated using PFACs in batch.

\subsection{BOD AND COD VARIATION WITH PH IN BATCH EXPERIMENT}

$50 \mathrm{mls}$ of VOIE with a known BOD and COD and respectively were place in five conical flasks in which five $1 \mathrm{gms}$ of PFAC have been previously weighed and placed. The $\mathrm{pH}$ of the solutions was adjusted with $0.5 \mathrm{M} \mathrm{HCl}$ and $0.1 \mathrm{M} \mathrm{NaOH}$ solutions to obtain $\mathrm{pHs}$ of $2,4,6,8,10,12$ respectively. 
The solutions adjusted pHs were then tightly covered with aluminium foil and agitated. At the expiration of $1 \mathrm{hr}$ the solutions were filtered using What man No 41centrifugation at 1000rpm for 10 mins, decanted and BOD and COD in turns read with a digital BOD manometer. This procedure was repeated for PFACs in batch and results were recorded (Brooks bank et al., 2007).

\subsection{BOD AND COD VARIATION WITH TEMPERATURE USING PFAC}

$50 \mathrm{ml}$ of VOIE with BODi and CODi were measured into five $250 \mathrm{ml}$ conical flask in which $1 \mathrm{~g}$ of PFAC were previously weighed and placed. The conical flask labelled 10, 20, 30, 40, 50, 60 and 70 degrees centigrade. The flasks were properly covered using aluminium foil, agitated with hand for 2 mins and heated on a thermostatic water bath to their appropriate temperatures. The solutions were centrifuged at $1000 \mathrm{rpm}$ for $5 \mathrm{mins}$, decanted and then BOD and COD values read using a BOD and COD manometer model.

\section{RESULTS AND DISCUSSION}

\subsection{Characteristics of Prepared Carbons}

The characteristics ofactivated carbon depend on the physical and chemical properties of the raw materialsas well as activation method used Lua and Guo, (2001). Nine parameters were determined for commercial activated carbon (CAC), PFAC using standard methods. Tables 4.9 Shows characteristics of ACs are prepared from fluted pumpkin seed shell (FPSS). FAC 1 to $\mathrm{FAC}_{5}$ were prepared by physical activation at same temperature as the carbonized biomass. The temperatures of carbonization and activation were carefully selected to maximize development of carbon molecular architecture.

The range of changes in the properties of activated carbons depends on the type of raw materials used, the way of obtaining them, the conditions of activation process (Johnset al., 1999; Buczek et al., 2000). All carbons characterized were of a particle size range of 106-300 $\mu \mathrm{m}$ using same materials and keeping time of activation constant. The finer the particle size of an $\mathrm{AC}$, the better the access to the surface area and the faster the rate of adsorption (Collin and Yii, 2008). Careful consideration of particle size distribution can provide significant operating benefits (Gimba and Musa, 2007).It is believed therefore that the changes in adsorption capacity and characteristics of prepared ACs will arise from activation processes, reagent and temperature and not as a result of particle size.

The $\mathrm{pH}$ values of $\mathrm{PFAC}_{\mathrm{s}}$ were generally acidic and range from $6.3\left(\mathrm{FAC}_{3}\right)$ to $6.8\left(\mathrm{FAC}_{4}\right)$ except $\mathrm{FAC}_{5}$ (7.6) that was slightly alkaline. Carbons of $\mathrm{pH}$ 6-8 are useful for most applications (Khadija et al., 2008 and Okieimen et al., 2007). Therefore all five carbons could be acceptable for most applications involving adsorption. Distinctly acidic ACs are not desirable (Paton, 1983 and Ahmedna et al., 2006). The $\mathrm{pH}$ of commercial activated carbon of 8.8 is higher than that of all thermally prepared fluted pumpkin activated carbon (Khadija et al, 2008).

In comparison to the commercial activated carbons most carbons prepared in this study exhibit high conductivity values thereby supposing that an acid and water wash were not enough to reduce leachable ash to levels observed in commercial carbons. The results of electrical conductivity indicates that even though the tested samples were acid or water washed substantial amounts of water soluble minerals remained in the ACs. Such high leach able mineral contents are unacceptable more so, for uses such as commercial sugar decolorization since ash is considered an impurity. Ash content is the indicator of the quality of an activated carbon. The order of decreasing surface area in $\mathrm{m}^{2} / \mathrm{g}$ was: $\mathrm{FAC}_{5}<\mathrm{FAC}_{2}<\mathrm{FAC}_{4}<\mathrm{FAC}_{3}<\mathrm{FAC}_{1}$.

Bulk density is a physical property that determines filterability of a carbon. It is the mass of carbon that can be contained in a filter of a given solid capacity and the amount of treated liquid that can be retained by the filter cake. The higher the density the better the filterability of activated carbons. The American Water Work Association has set a lower limit on bulk density at $0.25 \mathrm{gm} / \mathrm{ml}$ for GACs to be of practical use. (AWWA, 1991).The bulk density of all ACs were higher than this value, and generally increased from lower temperature activated carbons to higher temperature ones. Pore volume for $\mathrm{PFAC}_{\mathrm{s}}$ increased in the order; $\mathrm{FAC}_{1}>\mathrm{FAC}_{2}$ and $\mathrm{FAC}_{4}>\mathrm{FAC}_{3}>\mathrm{FAC}_{5}$. Porosity determines adsorptive capacity and it could predict that chemically prepared ACs will perform better than PFACs since larger pore volumes are advantageous in removing larger molecules from aqueous media. 
Removal of Biochemical and Chemical Oxygen Demands in Vegetable Oil Industry Effluents using Adsorbents from Fluted Pumpkin Mesocarp

Table1: Isotherm parameters of BOD and COD adsorption of VOIE onto PFACS

\begin{tabular}{|c|c|c|c|c|c|c|c|c|c|c|}
\hline \multicolumn{3}{|c|}{$\begin{array}{l}\text { Freundlich constants of } \\
\text { BOD }\end{array}$} & \multicolumn{2}{|c|}{$\begin{array}{l}\text { Freundlich } \\
\text { constants of COD }\end{array}$} & \multicolumn{3}{|c|}{ constants of } & \multicolumn{3}{|c|}{$\begin{array}{l}\text { Langmuir constants of } \\
\text { COD }\end{array}$} \\
\hline $\mathrm{ACs}$ & $\mathrm{n}$ & $\mathrm{Kf}$ & $\mathrm{n}$ & $\mathrm{Kf}$ & $\mathrm{q}_{\mathrm{m}}(\mathrm{m}$ & $\mathrm{K}_{2}(\mathrm{~L} / \mathrm{g}$ & $\mathrm{R}_{\mathrm{L}}$ & $\mathrm{q}_{\mathrm{m}}(\mathrm{mg} /$ & $\mathrm{K}_{2}(\mathrm{~L} / \mathrm{g})$ & $\mathrm{R}_{\mathrm{L}}$ \\
\hline $\mathrm{FAC}_{1}$ & 0.4300 & 2.16 & 300 & 2.400 & 493 & & & 0.4895 & & 015 \\
\hline $\mathrm{I} C \mathrm{C}$ & & & & & & & & & & \\
\hline$\overline{\mathrm{FA}}$ & & & & & & & & & & \\
\hline FAC & & & & & & & & & & \\
\hline $\mathrm{FAC}_{5}$ & 1.7240 & 1.085 & 71 & -0.5 & 15 & 0.16 & 0.0 & .50 & 3.2849 & 0.1 \\
\hline \multicolumn{3}{|c|}{$\begin{array}{l}\text { Tempkin constants of } \\
\text { BOD }\end{array}$} & \multicolumn{2}{|c|}{$\begin{array}{l}\text { Tempkin } \\
\text { constants of COD }\end{array}$} & \multicolumn{3}{|c|}{ D-R constants of BOD } & \multicolumn{3}{|c|}{ D-R constants of COD } \\
\hline \multicolumn{3}{|c|}{$\mathrm{ACs} \quad \mathrm{K}_{\mathrm{T}} \beta_{1}$} & \multicolumn{2}{|c|}{$\begin{array}{ll}\mathrm{K}_{\mathrm{T}} & \beta_{1} \\
\end{array}$} & \multicolumn{3}{|c|}{$X_{\mathrm{m}}(\mathrm{mg} / \mathrm{g}) \quad \beta\left(\mathrm{J}^{2}\right)$} & \multicolumn{2}{|c|}{$X_{m}(\mathrm{mg} / \mathrm{g}) \quad \beta\left(\mathbf{J}^{2}\right)$} & $\mathrm{J})$ \\
\hline & & & & & & 0.08 & & & & \\
\hline$\overline{F A C}$ & & & & & & & & & & \\
\hline $\mathrm{FAC}_{3}$ & & & & & & & & & & \\
\hline FAC & & & & & & 0. & & & 0.9 & \\
\hline $\mathrm{FAC}_{5}$ & 0.0043 & 18.33 & 0.0025 & 29.40 & 2.174 & 0.8 & -7.90 & 5.966 & 0.800 & +2.500 \\
\hline
\end{tabular}

ACs : Activated carbon sample; $n:$ Adsorption intensity; Kf: Adsorption capacity; $R_{L}$ : equilibrium parameter; $K_{L}$ : Adsorption energy constant. $q_{m}$ : max. adsorption, $K_{T:}$ Adsorption intensity; $\beta$ : Adsorption capacity

\subsection{ISOTHERM STUDIES}

The sorption equilibrium data was subjected to Freundlich isotherm analysis, Dubinin - Radushkevich (D-R) Temkin and Langmuir models. Data generated was easily plotted and the resulting plots were characterized by such parameters as adsorption intensity (n) from the slope $(1 / n)$, the adsorption capacity $\left(\mathrm{K}_{\mathrm{F}}\right)$, Maximum sorption capacity $\left(\mathrm{q}_{\mathrm{m}}\right)$, adsorption/ desorption constant energy $\left(\mathrm{K}_{\mathrm{L}}\right)$ and regression coefficient $\left(\mathrm{R}^{2}\right)$. The Freundlich sorption constants calculated from the slopes and intercepts and regression coefficients are shown in table 1.

From table 1, the adsorption intensity (n) was found to be highest for $\mathrm{FAC}_{5}(1.7240)$ and lowest for $\mathrm{FAC}_{3}(0.1737)$. A favorable adsorption correspond to an adsorption intensity of $1<\mathrm{n}<10$. Therefore the sorption process of BOD pollutants represented by Freundlich isotherm models constant for $\mathrm{FAC}_{5}$ (1.085) were favorable while unfavorable for all $\mathrm{FAC}_{1}$ to $\mathrm{FAC}_{4}$.

The trend of favored adsorption process from vegetable oil industry effluent using physically prepared activated carbon in terms of $\mathrm{BOD}$ as indicated by $\mathrm{n}$ values is as follows:

$\mathrm{FAC}_{3}>\mathrm{FAC}_{4}>\mathrm{FAC}_{1}>\mathrm{FAC}_{2}>\mathrm{FAC}_{5}$

The adsorption capacity, $\left(\mathrm{K}_{\mathrm{F}}\right)$ values shown on table 1 reveal that $\mathrm{FAC}_{5}$ (1.724) had highest adsorption capacity followed by $\mathrm{FAC}_{2}(0.8926)$ while $\mathrm{FAC}_{3}(0.1737)$ showed lowest value. $\mathrm{K}_{\mathrm{F}}$ values for the adsorption process here were similar those reported by Adesola et al., 2008.

The regression coefficient $\left(\mathrm{R}^{2}\right)$ ranged from $\mathrm{FAC}_{3}(0.2139)$ to $\mathrm{FAC}_{4}(0.9028)$. Fitness of Freundlich adsorption model in describing the adsorption of organic pollutants from vegetable oil industry effluents in terms of BOD using physically prepared active carbons followed the trend: $\mathrm{FAC}_{4}(0.9028)$ $>\mathrm{FAC}_{5}(0.7401)>\mathrm{FAC}_{1}(0.7358)>\mathrm{FAC}_{2}(0.7154)>\mathrm{FAC}_{3}(0.2139)$

Table 1 shows that the adsorption intensities of physically prepared activated carbon in terms of COD ranged from $\mathrm{FAC}_{3}(2.1900)$ to $\mathrm{FAC}_{1}(0.2300)$. Adsorption intensity of $1<\mathrm{n}<10$ indicate favourable sorption process, therefore all physically prepared activated carbon reveal favourable adsorption with the trend:

$\operatorname{FAC}_{3}(2.190)>\operatorname{FAC}_{2}(0.9500)>\operatorname{FAC}_{4}(0.8784)>\operatorname{FAC}_{5}(0.7191)>\operatorname{FAC}_{1}(0.2300)$.

The adsorption capacities $\left(\mathrm{K}_{\mathrm{F}}\right)$ in table 1 reveal that except for $\mathrm{FAC}_{5}(0.5738)$, all other carbon gave positive adsorption capacity that ranged from $\mathrm{FAC}_{1}(2.400)$ as highest to the least $\mathrm{FAC}_{4}(0.3613)$. In terms of fitness of adsorption data into Freundlich isotherm model $\mathrm{FAC}_{1}(0.9506)$ showed highest fitness whereas $\mathrm{FAC}_{3}(0.3180)$ had poor fitting. Recalling that higher regression coefficient indicate better fitness, therefore the order of best fit and suitability for describing the sorption process using Freundlich isotherm model was revealed to be:

$\operatorname{FAC}_{1}(0.9506)>\operatorname{FAC}_{4}(0.9311)>\operatorname{FAC}_{5}(0.81311)>\operatorname{FAC}_{2}(0.7960)>\operatorname{FAC}_{3}(0.3180)$. 
The sorption capacity $\left(\mathrm{q}_{\mathrm{m}}\right)$ measures the maximum adsorption capacity corresponding to complete monolayer coverage. Table 1 shows that values qm for PFAC in terms of BOD followed the decreasing order;

$\mathrm{FAC}_{3}(760)>\mathrm{FAC} 4(658.7)>\mathrm{FAC}_{5}(615)>\mathrm{FAC}_{1}$ (493.) $>\mathrm{FAC}_{2}(377)$

These high values of qm indicate large adsorbent surface area (Adediran et al., 2000).

The apparent sorption energy constant $\mathrm{K}_{\mathrm{L}}(\mathrm{L} / \mathrm{g})$ does not follow the same trend. Values of $\mathrm{K}_{\mathrm{L}}$ with respect to BOD using physically prepared activated carbon were low, which suggests that the sorption of organic pollutants from vegetable oil industry effluents measured in terms of BOD was a favorable process. This results are consistent with those obtained by Tarawou, 2009, who maintained that the lower the apparent energy of sorption, the more favorable the sorption process. Note that small values of $\mathrm{K}_{\mathrm{L}}$ indicate effective adsorption at low solution concentration. In the present study the order of increasing values of apparent sorption energy was:

$\mathrm{FAC}_{2}(0.0144)<\mathrm{FAC}_{1}(0.0615)<\mathrm{FAC}_{4}(0.1455)<\mathrm{FAC}_{5}(0.1608)<\mathrm{FAC}_{3}(0.1760)$.

Based on apparent sorption energy, $\mathrm{FAC}_{2}$ would provide the most favorable sorption process while $\mathrm{FAC}_{3}$ would be the least favored sorption process.

From table 1 the regression coefficients $\left(\mathrm{R}^{2}\right)$ obtained in terms of BOD of vegetable oil industry effluents using physically prepared activated carbon were generally low. These $\mathrm{R}^{2}$ values ranged from 0.017 in $\mathrm{FAC}_{3}$ to 0.4854 in $\mathrm{FAC}_{2}$. The order of increasing $\mathrm{R}^{2}$ values is as follows:

FAC $_{3}(0.017)<$ FAC $_{1}(0.0218)<$ FAC $_{5}(0.4340)<\mathrm{FAC}_{4}(0.4816)<\mathrm{FAC}_{2}(0.4854)$.

According to Ambrose et al., 2011, levels of fitness are indicated as follows, $\mathrm{R}^{2}=1$ perfect fit, $\mathrm{R}^{2}$ between $\mathrm{R}^{2}=0.5-0.9$ good fit and $\mathrm{R}^{2}=0-0.4$ poor fit. The poor fit of Langmuir model exhibited by regression coefficient values in table 1 suggest that perhaps the Langmuir isotherm was not suitable for describing the adsorption of organic pollutants in vegetable oil industry effluents in terms of BOD using physically prepared activated carbon.

According to Maliek, 2004, an essential characteristic of Langmuir isotherm can be expressed in terms of a dimensionless separation factor or equilibrium parameter, $\mathrm{R}_{\mathrm{L}}$ and defined as

$\mathrm{R}_{\mathrm{L}}=1 / 1+\mathrm{bC}_{\mathrm{o}} \ldots \ldots \ldots$

Where $b$ is a Langmuir constant $(\mathrm{L} / \mathrm{g})$ and $\mathrm{C}_{\mathrm{o}}$ is the initial concentration of the specie undergoing adsorption.

Table 1 shows the calculated values of $R_{L}$ to range from 0.00027 in $F_{A} C_{2}$ to 2.7707 , for $F_{A C}$. However the sorption process is considered unfavorable if $R_{L}>1$, linear if $R_{L}=1$, favorable if $0<R_{L}<$ 1 and finally irreversible if $\mathrm{R}=0$. In the light of these considerations, $\mathrm{FAC}_{1}$ equilibrium parameter of 2.7707 indicates that the sorption process described by Langmuir isotherm for the adsorption of organic pollutants from vegetable oil industry effluent was unfavorable. This was an anomaly shown by $\mathrm{FAC}_{1}$, where as all others PFACs showed favorable adsorption processes in the increasing order: $\mathrm{FAC}_{3}$ and $\mathrm{FAC}_{4}(0.00024)<\mathrm{FAC}_{5}(0.00025)<\mathrm{FAC}_{2}$.

It can be noted that using the Langmuir isotherm described adsorption processes generally was favorable.

Table 1 shows that maximum sorption capacities $\left(\mathrm{q}_{\mathrm{m}}\right)$ in $\mathrm{mg} / \mathrm{g}$ for physically prepared activated carbon ranged from $\mathrm{FAC}_{3}$ (1.89) to $\mathrm{FAC}_{2}$ (0.685). Except for $\mathrm{FAC}_{3}$ (189) these values could be described as representing a satisfactory surface area for sorption in fluted pumpkin seed shell activated carbon samples. The order of increasing surface area then can be:

FAC $_{3}(1.89)<\mathrm{FAC}_{5}(0.382)<\mathrm{FAC}_{1}(0.489)<\mathrm{FAC}_{4}(0.656)<\mathrm{FAC}_{2}(0.685)$.

The calculated apparent sorption energy constant $\mathrm{K}_{\mathrm{L}}(\mathrm{L} / \mathrm{g})$ for this process ranged from $\mathrm{FAC}_{1}(0.062)$ to $\mathrm{FAC}_{4}$ (4.052). It can be observed that the values are low, indicating favourable sorption processes. The trend of increasing apparent sorption energy was

$\mathrm{FAC}_{1}(0.062)<\mathrm{FAC}_{3}(0.279)<\mathrm{FAC}_{2}(0.288)<\mathrm{FAC}_{5}(3.285)<\mathrm{FAC}_{4}(4.052)$

The regression coefficients, $\mathrm{R}^{2}$ (table 1 ) obtained in this process showed good fitness for Langmuir model except for $\mathrm{FAC}_{1}(0.1203)$. $\mathrm{FAC}_{4}(0.99)$ showed highest fitness followed by $\mathrm{FAC}_{2}(0.872)$, followed by $\mathrm{FAC}_{5}(0.842)$ and finally $\mathrm{FAC}_{3}(0.785)$. Equilibrium parameters, $\left(\mathrm{R}_{\mathrm{L}}\right)$ for the process in table 1 showed that all activated carbon samples had favourable sorption process with values of $\mathrm{R}_{\mathrm{L}}$ as low as $\mathrm{FAC}_{1}(0.00098)$ and high as in $\mathrm{FAC}_{4}(0.00025)$. 
Employing the concept of equilibrium parameter, $\mathrm{R}_{\mathrm{L}}$ as used by Malik, 2004, it was concluded that all five chemically prepared activated carbon exhibited favorable sorption processes. Values of $R_{L}$ shown in table 1 fall within the favorable range of $0<\mathrm{R}_{\mathrm{L}}<1$. These results are in agreement with works done by Kumar et al., (2005) and Tarawou, (2009).

\subsection{TEMKIN ISOTHERM}

Using equation for the Temkin isotherm model new equations in terms of BOD and COD were written as equation 2 and 3 respectively.

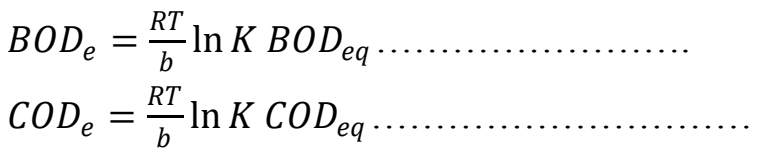

$\mathrm{BOD}_{\mathrm{e}}$ and $\mathrm{COD}_{\mathrm{e}}$ : amount of sorbate/mass of carbon and $\mathrm{BOD}_{\mathrm{eq}}$ and $\mathrm{COD}_{\mathrm{eq}}$ are equilibrium values. Plots of $\mathrm{BOD}_{\mathrm{e}}$ agianst $\ln \mathrm{BOD}_{\mathrm{e}}$ and $\mathrm{COD}_{\mathrm{e}}$ against $\ln \mathrm{COD}_{\mathrm{eq}}$ gave figures (Verla, 2013). The slopes and intercepts of these plots were used to determine Temkin isotherm parameters.

Table 1 shows the Temkin isotherm parameters for PFAC in terms of BOD, the equilibrium binding energy constant $\left(\mathrm{K}_{\mathrm{T}}\right)$ corresponding to the maximum binding energy of sorbent and sorbate, the constant $\beta_{1}$ related to the heat of sorption and regression values $R^{2}$. The $K_{T}$ values of PFAC range between $\mathrm{FAC}_{1}(0.0001 \mathrm{~J} / \mathrm{mg})$ to $\mathrm{FAC}_{2}(0.9999 \mathrm{~J} / \mathrm{g})$. This indicates that little energy was involved in the sorption processes. The $\beta_{1}$ values are equally small, and ranged from $\mathrm{FAC}_{1}(0.353)$ to $\mathrm{FAC}_{3}(0.252)$. $\mathrm{R}^{2}$ values ranged from $\mathrm{FAC}_{3}(0.252)$ to $\mathrm{FAC}_{4}(0.966) . \mathrm{FAC}_{2}, \mathrm{FAC}_{5}$ and $\mathrm{FAC}_{4}$ had $\mathrm{R}^{2}$ values higher than 0.800 indicating good fit into the Temkin isotherm.

Table 1 shows $K_{T}$, and $\beta_{1}$ values of PFAC in terms of COD. The $K_{T}$ values were small and ranged from $\mathrm{FAC}_{4}(0.0014)$ to $\mathrm{FAC}_{1}(0.0107)$ while $\beta_{1}$ values ranged from $\mathrm{FAC}_{1}(95.84)$ to $\mathrm{FAC}_{4}(34.10)$. The regression values showed good fit with $\mathrm{R}^{2}$ greater than 0.8 except for $\mathrm{FAC}_{3}(0.496)$.

\subsection{DUBININ-RADUSHKEVIC (D-R) ISOTHERM}

The linear form of $\mathrm{D}-\mathrm{R}$ is othererm model was written first in terms of $\mathrm{BOD}_{\mathrm{e}}$ and secondly in terms of $\mathrm{COD}_{\mathrm{e}}$ to give equations 4 and 5 respectively.

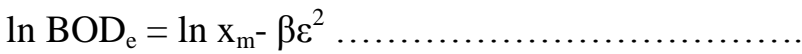

$\ln \mathrm{COD}_{\mathrm{e}}=\ln \mathrm{x}_{\mathrm{m}}-\beta \varepsilon^{2}$

$\mathrm{BOD}_{\mathrm{e}}$ and $\mathrm{COD}_{\mathrm{e}}$ are amounts of sorbate/mass of carbon and $\mathrm{BOD}_{\mathrm{eq}}$ and $\mathrm{COD}_{\mathrm{eq}}$ represent the equilibrium concentrations. The Polanyi potential was determined using equation 4 and 5 and by plotting $\ln \mathrm{BOD}_{\mathrm{e}}$ against $\varepsilon^{2}$ revealed graphswhose the intercepts and slopes gave the $\mathrm{D}-\mathrm{R}$ parameters of both PFAC interms BODs and COD respectively.

Dubinin - Radushkevic ( $\mathrm{D}-\mathrm{R})$ isotherm parameters in terms of BOD of the different PFACs are presented in table 1 . Values of maximum sorption capacities $\left(\mathrm{X}_{\mathrm{m}}\right)$ ranged from $\mathrm{FAC}_{1}(1.764 \mathrm{mg} / \mathrm{g})$ to $\mathrm{FAC}_{2}(6.03 \mathrm{mg} / \mathrm{g})$. These values indicate that Van der Waals forces were equally involved in adsorption processes and that the mechanism of sorption was pore-filling in nature (Dubinin and Radushkevich, 1947). The values of activity coefficient $(\beta)$ for $\mathrm{PFAC}_{3}$ were basically similar and ranged from $\mathrm{FAC}_{1}\left(0.8 \mathrm{~J}^{2}\right)$ to $\mathrm{FAC}_{3}\left(0.09 \mathrm{~J}^{2}\right)$. The activity coefficient directly relate to sorption energy via the expression (Shah et al., 2011; Horsfall and Spiff, 2004a).

$$
E=\frac{-1}{-2 \beta^{1 / 2}} \ldots \ldots \ldots \ldots \ldots \ldots \ldots \ldots
$$

Hence values for $\mathrm{E}$ calculated for $\mathrm{FAC}_{\mathrm{I}}$ to $\mathrm{FAC}_{5}$ are shown on table 4.35. Except for $\mathrm{FAC}_{5}(-7.90 \mathrm{KJ})$, all physically prepared activated carbon showed $\mathrm{E}$ values ranging from -2.4 to $-2.5 \mathrm{KJ}$. The negative values of $E$ indicate that the sorption process was exothermic which favours sorption at lower solution temperatures. Since the values of energy of sorption are lower than - $40 \mathrm{KJ} / \mathrm{mol}$ it could be inferred that physico-sorption process was involved (Horsfall and Spiff, 2005c). The regression values $\left(\mathrm{R}^{2}\right)$ showed poor fit for $\mathrm{FAC}_{3}(0.084)$ and $\mathrm{FAC}_{1}(0.331)$ whereas $\mathrm{FAC}_{5}(0.770), \mathrm{FAC}_{2}(0.774)$ and $\mathrm{FAC}_{4}$ (0.919) showed better fit of equilibrium data to the $(\mathrm{D}-\mathrm{R})$ isotherm expression.

Table 1 represents the $\mathrm{D}-\mathrm{R}$ isotherm parameters of physically prepared activated carbon in terms of COD. The $X_{\mathrm{m}}$ values here were generally low, ranging from $\mathrm{FAC}_{1}(0.024 \mathrm{mg} / \mathrm{g})$ to $\mathrm{FAC}_{5}(5.966 \mathrm{mg} / \mathrm{g})$. The $\beta$ values ranged from $\mathrm{FAC}_{3}(0.09)$ to $\mathrm{FAC} 4(0.900)$ while $\mathrm{E}$ values varied from $\mathrm{FAC}_{4}(0.746 \mathrm{KJ})$ 
to $\mathrm{FAC}_{1}(7.937 \mathrm{KJ})$. The $\mathrm{R}^{2}$ values showed poor fit for $\mathrm{FAC}_{4}(0.218)$ whereas $\mathrm{FAC}_{1}(0.951), \mathrm{FAC}_{2}$ (0.855), $\mathrm{FAC}_{3}(0.796)$ and $\mathrm{FAC}_{5}(0.797)$ showed good fit of data into the $\mathrm{D}-\mathrm{R}$ isotherm.

The $\mathrm{D}-\mathrm{R}$ isotherm confirm that Van der Waals forces were involved in the adsorption and that for physically prepared activated carbon with respect to BOD, the sorption processes were exothermic while all others were having positive $\mathrm{E}$ values indicating endothermic process. Equilibrium data didn't show good fit and therefore $\mathrm{D}-\mathrm{R}$ isotherm may not be very useful in the designe of sorption equipment in the case of BOD or COD.

\subsection{KINETICS OF BOD AND COD REMOVAL FROM VEGETABLE OIL INDUSTRY EFFLUENT}

\subsubsection{Pseudo-first order kinetics}

Using equation the plots of $\log \mathrm{BOD}_{\mathrm{eq}}-\mathrm{BOD}_{\mathrm{t}}$ against time and $\log \mathrm{COD}_{\mathrm{eq}}-\mathrm{COD}_{\mathrm{t}}$ against time for PFAC gave graphs that were analyzed to obtain the desired parameters.

$$
\begin{aligned}
& \log \left(q_{s q}-q\right)-\log q_{s q}-\frac{K_{1}}{2.303} t \ldots \ldots . . \\
& 1 / q_{t}-\frac{1}{h_{o}}+\left(\frac{1}{q_{s}}\right) t \ldots \ldots \ldots \ldots \ldots \ldots . .
\end{aligned}
$$

From these plots the pseudo-first order rate constants in terms of BOD and COD, $\mathrm{K}_{1} \mathrm{~B}$ and $\mathrm{K}_{1} \mathrm{C}$ respectively and corresponding sorption capacities $\mathrm{q}_{\mathrm{BOD}}$ and $\mathrm{q}_{\mathrm{COD}}$ were determined.

The pseudo-first order rate constant $\mathrm{K}_{1} \mathrm{~B}$ for all PFAC were negative (table 2) ranging from FAC $_{2}\left(1.68 * 10^{-2}\right)$ to $\operatorname{FAC}_{1}\left(-3.6 * 10^{-2}\right)$. These rates constant had the same order of magnitude. This showed that the rate constant were independent of initial value of BOD. The equilibrium sorption capacities $\left(\mathrm{q}_{\mathrm{BOD}}\right)$ of the processes ranged from $\mathrm{FAC}_{2}\left(1585 \mathrm{mgl}^{-1} \mathrm{~g}^{-1}\right)$ to $\mathrm{FAC}_{1}\left(6309 \mathrm{mgl}^{-1} \mathrm{~g}^{-1}\right)$. These values are in agreement with adsorption in terms of BOD. These results are further confirmed by regression values $\mathrm{R}^{2}$ which ranged from $\mathrm{FAC}_{2}(0.8341)$ to $\mathrm{FAC}_{1}(0.9248)$. Results indicate that the pseudo-first order model (Lagergren rate equation) was good for describing the sorption of organic pollutants from aqueous effluents of vegetable oil industry in terms of BOD.

The pseudo-first order kinetic parameters of PFAC in terms of COD showed that the $\mathrm{K}_{1} \mathrm{C}$ values ranged from $\mathrm{FAC}_{3}\left(1.2^{*} 10^{-2}\right)$ to $\mathrm{FAC}_{4}\left(4.15^{*} 10^{-2} \mathrm{mgl}^{-1} \mathrm{~g}^{-1} \mathrm{~min}^{-1}\right)$ while the $\mathrm{q}_{\mathrm{COD}}$ values ranged from $\mathrm{FAC}_{4}$ (501)to $\mathrm{FAC}_{1}, \mathrm{FAC}_{2}$ and $\mathrm{FAC}_{5}\left(7079 \mathrm{mgl}^{-1} \mathrm{~g}^{-1}\right)$. Regression analysis showed least values for $\mathrm{FAC}_{4}(0.4078)$ and highest for $\mathrm{FAC}_{1}(0.9142)$. Again these results agree and indicated a suitable fit for describing the sorption process in terms of COD.

However, the results in terms of BOD data show greater acceptability than those of COD kinetic studies for PFAC.

\subsubsection{Pseudo second kinetics}

From equation literature deduction, the pseudo second order kinetic rate expression in terms of BOD and COD was written as equation 9 and 10 respectively.

$\frac{t}{B O D_{t}}=\frac{1}{h_{0}}+\frac{1}{B O D_{\theta}}$

$\frac{t}{\operatorname{COD}_{t}}=\frac{1}{h_{0}}+\frac{1}{\operatorname{COD}_{\theta}}$

Where BODt is BOD recorded at time $t$ on surface of FPSSAC and BODe is the amount of BOD at equilibrium, CODt and CODe follow same. The initial sorption capacities, ho were calculated from equation 11 and 12

$h_{o}=k_{2} B O D_{\theta}^{2}$

$h_{\circ}=k_{2} C O D_{\theta}^{2}$

The parameters $k 2$,ho were determined from slopes and intercept of plots of t/BODt against time ( $t$ ) and $\mathrm{t} / \mathrm{CODt}$ against time $(\mathrm{t})$. 
The pseudo-second order sorption model is equally time dependent. It considers the rate determining step as the formation of chemisorptions bonds. Thus the bonds between the sorbate and sorbent involves sharing or exchange of electrons. According to Ho and McKay, (1998) this model predicts the behavior over the whole range of equilibrium experimental data to give good plots of $t / \mathrm{BOD}_{\mathrm{t}}$ against $t$ and are $t / \mathrm{COD}_{t}$ against $t$ on figures respectively for PFAC. From these plots the equilibrium sorption parameters, the rate constants $\mathrm{K}_{2} \mathrm{~B}$ and $\mathrm{K}_{2} \mathrm{C}$ and the regression values were obtained.

Table 2 shows that the equilibrium sorption capacity $\mathrm{BOD}_{\mathrm{eq}}$ values ranged from $\mathrm{FAC}_{1}(557)$ to $\mathrm{FAC}_{3}$ $\left(1667 \mathrm{mgl}^{-1} \mathrm{~g}^{-1}\right)$. The equilibrium sorption capacity $\left(\mathrm{COD}_{\mathrm{eq}}\right)$ decreases in the order:

$\mathrm{FAC}_{3}(1667)>\mathrm{FAC}_{2}(1111)>\mathrm{FAC}_{4}(833)>\mathrm{FAC}_{5}(769)>\mathrm{FAC}_{1}(557)$

Table 2 equally shows that the sorption equilibrium capacity for $\mathrm{FAC}$ in terms of $\mathrm{COD}_{\mathrm{eq}}$ was highest for $\mathrm{FAC}_{2}(2000)$ followed by $\mathrm{FAC}_{4}$ and $\mathrm{FAC}_{5}$ with same values $\left(1667 \mathrm{mgl}^{-1} \mathrm{~g}^{-1}\right)$.

The sorption equilibrium capacity $\mathrm{COD}_{\mathrm{eq}}$ decreased in the order:

$\mathrm{FAC}_{2}(2000)>\mathrm{FAC}_{4}$ and $\mathrm{FAC}_{5}(1667)>\mathrm{FAC}_{3}(1167)>\mathrm{FAC}_{1}(909)$.

The pseudo-second order rate constant in terms of BOD written as $\mathrm{K}_{2} \mathrm{~B}$ had highest value for $\mathrm{FAC}_{1}(-$ $\left.5.22 * 10^{-5} \mathrm{mgl}^{-1} \mathrm{~g}^{-1} \mathrm{~min}^{-1}\right)$ while the lowest value was recorded for $\mathrm{FAC}_{3}\left(-1.44 * 10^{-5}\right)$. The pseudosecond order rate constant decreases in the order:

$\operatorname{FAC}_{1}\left(-5.22 * 10^{-5}>\operatorname{FAC}_{5}\left(-4.05 * 10^{-5}>\right.\right.$ FAC $_{2}\left(-3.85^{*} 10^{-5}>\right.$ FAC $_{4}\left(-3.74 * 10^{-5}>\right.$ FAC $_{3}\left(-1.44 * 10^{-5}\right)$.

In terms of $\mathrm{COD}$, the pseudo-second order rate constant $\mathrm{K}_{2} \mathrm{C}$ was highest for $\mathrm{FAC}_{1}\left(3.37 * 10^{-5}\right)$ and lowest for $\mathrm{FAC}_{2}\left(-1.69 * 10^{-5}\right)$. Values show that $\mathrm{FAC}_{2}\left(1.69 * 10^{-5} ; \mathrm{FAC}_{3}\left(-1.79 * 10^{-5} ; \mathrm{FAC}_{5}\left(-1.70 * 10^{-5}\right.\right.\right.$ and $\mathrm{FAC}_{4}\left(-201 * 10^{-5}\right.$ were generally the same. The regression values for $\mathrm{BOD}_{\mathrm{eq}}$ showed good agreement as they all ranged from $\mathrm{FAC}_{5}(0.607)$ to $\mathrm{FAC}_{3}(0.874)$.

In terms of $\mathrm{COD}$ the regression values ranged from $\mathrm{FAC}_{5}(0.732)$ to $\mathrm{FAC}_{3}(0.928)$. It was observed that the regression values in terms of COD exhibited better agreement than the case of BOD. However, the regression values were generally between 0.6 and 0.7 except for $\mathrm{FAC}_{2}$ and $\mathrm{FAC}_{3}$ that the values were above 0.8 . It can therefore be said that even though the sorption processes conform to pseudo-second order kinetic model, the level of conformity was poor for most of PFAC except for $\mathrm{FAC}_{2}$ and $\mathrm{FAC}_{3}$.

Table2: Pseudo - First and second order Kinetic sorption parameters of BOD and COD onto PFACs

\begin{tabular}{|c|c|c|c|c|c|c|}
\hline \multicolumn{7}{|c|}{ Pseudo - First order Kinetic sorption parameter of PFAC } \\
\hline $\begin{array}{l}\text { Activated } \\
\text { Carbon }\end{array}$ & $\begin{array}{l}\mathrm{BOD}_{\mathrm{eq}} \\
\mathrm{mgl}^{-1} \mathrm{~g}^{-1}\end{array}$ & $\begin{array}{c}\mathrm{K}_{1} \mathrm{~B} \\
\mathrm{mgl}^{-1} \mathrm{~g}^{-1} \min ^{-1}\end{array}$ & $\begin{array}{c}\mathrm{R}^{2} \\
\text { Regression } \\
\text { value }\end{array}$ & $\begin{array}{l}\mathrm{COD}_{\mathrm{eq}} \\
\mathrm{mgl}^{-1} \mathrm{~g}^{-1}\end{array}$ & $\begin{array}{c}\mathrm{K}_{1} \mathrm{C} \\
\mathrm{mgl}^{-1} \mathrm{~g}^{-1} \min ^{-1}\end{array}$ & $\begin{array}{c}\mathrm{R}^{2} \\
\text { Regression value }\end{array}$ \\
\hline $\mathrm{FAC}_{1}$ & 6309 & $-3.6 \times 10^{-2}$ & 0.92480 & 7070 & $-2.2 \times 10^{-2}$ & 0.9142 \\
\hline $\mathrm{FAC}_{2}$ & 1585 & $-1.6 \times 10^{-2}$ & 0.8341 & 7079 & $3.06 \times 10^{-2}$ & 0.8316 \\
\hline $\mathrm{FAC}_{3}$ & 2820 & $-1.77 \times 10^{-2}$ & 0.8641 & 2512 & $1.2 \times 10^{-2}$ & 0.8422 \\
\hline $\mathrm{FAC}_{4}$ & 3981 & $-2.9 \times 10^{-2}$ & 0.8277 & 501 & $415 \times 10^{-2}$ & 0.4078 \\
\hline $\mathrm{FAC}_{5}$ & 1778 & $-2.5 \times 10^{-2}$ & 0.8324 & 7079 & $3.22 \times 10^{-2}$ & 0.8318 \\
\hline \multicolumn{7}{|c|}{ Pseudo - Second order Kinetic sorption parameters of CFAC } \\
\hline $\begin{array}{l}\text { Activated } \\
\text { Carbon }\end{array}$ & $\begin{array}{l}\mathrm{BOD}_{\mathrm{eq}} \\
\mathrm{mgl}^{-1} \mathrm{~g}^{-1}\end{array}$ & $\begin{array}{c}\mathrm{K}_{2} \mathrm{~B} \\
\mathrm{mgl}^{-1} \mathrm{~g}^{-1} \min ^{-1}\end{array}$ & $\begin{array}{c}\mathrm{R}^{2} \text { Regresion } \\
\text { value }\end{array}$ & $\begin{array}{c}\mathrm{COD}_{\mathrm{eq}} \\
\mathrm{mgl}^{-1} \mathrm{~g}^{-1}\end{array}$ & $\begin{array}{c}\mathrm{K}_{2} \mathrm{C} \\
\mathrm{mgl}^{-1} \mathrm{~g}^{-1} \min ^{-1}\end{array}$ & $\begin{array}{c}\mathrm{R}^{2} \text { Regression } \\
\text { value }\end{array}$ \\
\hline $\mathrm{FAC}_{1}$ & 557 & $-5.22 \times 10^{-5}$ & 0.6738 & 909 & $-3.7 \times 10^{-5}$ & 0.7428 \\
\hline $\mathrm{FAC}_{2}$ & 1111 & $-3.85 \times 10^{-5}$ & 0.8674 & 2000 & $-1.69 \times 10^{-5}$ & 0.8521 \\
\hline $\mathrm{FAC}_{3}$ & 1667 & $-1.44 \times 10^{-5}$ & 0.8741 & 1167 & $-1.79 \times 10^{-5}$ & 0.9277 \\
\hline $\mathrm{FAC}_{4}$ & 833 & $-3.7 \times 10^{-5}$ & 0.6251 & 1667 & $-2.01 \times 10^{-5}$ & 0.7248 \\
\hline $\mathrm{FAC}_{5}$ & 769 & $-4.05 \times 10^{-5}$ & 0.6076 & 1667 & $-1.70 \times 10^{-5}$ & 0.7319 \\
\hline
\end{tabular}

\subsubsection{Sorption thermo dynamics}

The relationship between $\Delta \mathrm{H}^{\mathrm{o}}, \Delta \mathrm{S}^{\mathrm{o}}, \Delta \mathrm{G}^{\mathrm{o}}$ and $\mathrm{In} \mathrm{K}$ for a reaction given as in equation 13 .

In $K_{o}=\frac{\Delta 5^{D}}{R}-\frac{\Delta H^{0}}{R T}$ 
Removal of Biochemical and Chemical Oxygen Demands in Vegetable Oil Industry Effluents using Adsorbents from Fluted Pumpkin Mesocarp

A plot of $\ln \mathrm{K}_{\mathrm{o}}$ against $1 / \mathrm{T}$ where $\mathrm{K}_{\mathrm{o}}=\mathrm{BOD}_{\mathrm{eq}} / \mathrm{BOD}_{\mathrm{T}}$ and $\mathrm{COD}_{\mathrm{eq}} / \mathrm{COD}_{\mathrm{T}}$

In order to assess the effect of temperature on the sorption processes, thermodynamic parameters namely Gibbs free energy change $\left(\Delta \mathrm{H}^{0}\right)$ enthalpy change $\left(\Delta \mathrm{G}^{0}\right)$ enthropy $\left(\Delta \mathrm{S}^{0}\right)$ were determined from equations 13 .

Table3: Thermodynamic parameters of adsorption of BOD and COD from VOIE onto PFACs in Batch

\begin{tabular}{|c|c|c|c|c|c|c|c|c|}
\hline \multicolumn{5}{|c|}{ Thermodynamic parameter for BOD } & \multicolumn{4}{c|}{ Thermodynamic parameter for COD } \\
\hline $\begin{array}{c}\text { AC } \\
\text { sample }\end{array}$ & $\Delta \mathrm{G}_{273}$ & $\Delta \mathrm{G}_{373}$ & $\Delta \mathrm{H}^{\mathrm{o}}$ & $\Delta \mathrm{S}^{\mathrm{o}}$ & $\Delta \mathrm{G}_{293}$ & $\Delta \mathrm{G}_{343}$ & $\Delta \mathrm{H}^{\mathrm{o}}$ & $\Delta \mathrm{S}^{\mathrm{o}}$ \\
\hline $\mathrm{FAC}_{1}$ & 187.3 & 1654 & 9.121 & -31.50 & 96.91 & 1372 & 8.82 & -30.05 \\
\hline FAC $_{2}$ & 153 & 1633 & 9.49 & -32.50 & 67 & 2620 & 17.95 & -60.31 \\
\hline $\mathrm{FAC}_{3}$ & 268 & 3170 & 20.32 & -68.26 & 216.4 & 1909 & 11.63 & -39.68 \\
\hline FAC $_{4}$ & 246 & 2509 & 16.30 & -55.20 & 198 & 2729 & 18.03 & -61.11 \\
\hline FAC $_{5}$ & 286 & 2869 & 22.23 & -75.02 & 259.4 & 1941 & 11.94 & 40.89 \\
\hline
\end{tabular}

Values in $\mathrm{KJ} / \mathrm{mol}$

Two values $\Delta \mathrm{G}_{293}$ and $\Delta \mathrm{G}_{343}$ were calculated from the equation $\Delta \mathrm{G}=\ln \mathrm{K}_{\mathrm{o}}$ at lowest and highest temperature for each activated carbon. A liner plot of $\ln \mathrm{K}_{\mathrm{o}}$ against $1 / \mathrm{T}$ gave graphs that were used to evaluate the values of $\Delta \mathrm{H}^{\circ}$ and $\Delta \mathrm{S}^{\circ}$ from slope and intercept. The results obtained for $\mathrm{FAC}_{1}$ to $\mathrm{FAC}_{5}$ are shown on table 3 .

The $\Delta \mathrm{G}_{293}$ values for PFAC ranged from $\mathrm{FAC}_{5}$ (268) to $\mathrm{FAC}_{2}$ (153) while values for $\Delta \mathrm{G}_{343}$ ranged from $F A C_{3}$ (3170) to $F A C_{2}$ (1633). Table 3 reveal that values for $\Delta G_{293}$ were lower than for $\Delta G_{343}$.

The values of $\Delta$ Gfor both low and high temperatures are positive indicating that the overall process was spontaneous. $\Delta \mathrm{G} 343$ values are relatively high confirming the feasibility of using the physically prepared activated carbon in reducing BOD of vegetable oil industrial effluent. The values of $\Delta \mathrm{H}^{\circ}$ ranged from $\mathrm{FAC}_{1}$ (9.121) to $\mathrm{FAC}_{5}$ (22.23) were positive and low indicating an endothermic processes. However these values could be generally supplied by the environment, and therefore indicate that PFACs could be used in reducing BOD of vegetable oil industry effluents. Table 3 reveals that $\Delta \mathrm{S}^{\mathrm{o}}$ values were negative and relatively high confirming the formation of strong bonds between adsorbent and adsorbent. Therefore there was restricted freedom of the adsorbed molecules of organic components on the activated carbon, thus confirming some degree of chemisorptions.

Gibbs free energy of sorption of organic pollutants in terms of COD, from vegetable oil industry effluents PFAC was all positive. The $\Delta \mathrm{G}_{293}$ ranged from $\mathrm{FAC}_{2}$ (67) to $\mathrm{FAC}_{5}$ (259.4) while $\Delta \mathrm{G}_{343}$ vales ranged from $\mathrm{FAC}_{1}(1372)$ to $\mathrm{FAC}_{4}$ (2729). These values reveals that $\Delta \mathrm{G}_{343}$ were all higher than $\Delta \mathrm{G}_{293}$ for all activated carbon samples prepared by physical activation. Also these values show that the sorption processes were not spontaneous. Therefore chemisorptions was involved in binding of sorbet onto sorbents. Table 3 equally shows the enthalpy changes of sorption processes for PFACs. All $\Delta \mathrm{H}^{\circ}$ values here were positive with $\mathrm{FAC}_{4}$ (18.03) being the highest followed by $\mathrm{FAC}_{2}$ (17.95). $\mathrm{FAC}_{3}$ and $\mathrm{FAC}_{5}$ had slightly different values while $\mathrm{FAC}_{1}(8.82)$ was the lowest for all PFACs. Again these positive values indicate endothermic sorption processes. The entropy values for sorption processes were all positive and ranged from $\mathrm{FAC}_{1}(-30.05)$ to $\mathrm{FAC}_{4}$ (- 61.11). These negative values indicate strong bond formation between sorbets - sorbent molecules, thereby confirming chemisorptions as the major mechanism of sorption reaction. Therefore these results agree that the sorption processes at $\Delta \mathrm{G}_{293}$ were dominated by pseudo-second order kinetics.

\section{CONCLUSION}

Equilibrium data obtained in this work had best fit into the Freundlich isotherm model with regression coefficients ranging from 0.7358 to 0.9506 . Secondly, Tempkin isotherm parameters showed better regression coefficients and it could be said that the reduction of BOD and COD of vegetable oil industrial effluents using fluted activated carbon was better described by Temkin isotherm model. Although the Langmuir isotherm showed generally poor fit, the calculated quilibrium parameters $R_{L}$ showed that sorption was favored for CFAC. Poorest fit was observed for Dubenin-Raduskevic model. Kinetic parameters $\mathrm{K}_{1}$ and $\mathrm{K}_{2}$ for both BOD and COD revealed that sorption favored both pseudo-first order and pseudo-second order. Even though the regression value for some PFACs were low, all other AC samples showed good regression values for sorption process in terms of COD. 
Thermodynamics parameters showed positive values of $\Delta \mathrm{H}$, hence energy was required in the sorption processes. The adsorption process were not spontaneous as values were positive with adsorption at higher temperatures showing higher values of $\Delta \mathrm{G}$ while values of $\Delta \mathrm{S}$ were generally negative confirming that there was chemisorptions occurring.

\section{ACKNOWLEDGEMENT}

This work is completed as part of $\mathrm{PhD}$ thesis in the department of Pure and industrial chemistry, University of Port Harcourt. It was supported by the Chemistry laboratory, Madonna University and therefore all technologists there are gratefully acknowledged. We express deep gratitude to the Director; Centre for Energy Research University of Nigeria Nsukka, for the use of certain scientific instruments.

\section{REFERENCES}

[1] Adebayo, G. A. and Aloko, D. F. (2007). Production and characterisation of activated carbon from agricultural waste (Rice-husk and corn-cob). Journal of Engineering and Applied Sciences, 2(2), 440 - 444

[2] Adediran G. O. Nwosu F. O. and Adekola F. A. (2000). Some Langmiuir adsorption parameters of activated carbon produced from local materials. Nigerian Journal of pure and Applied Science, 15, 10751082.

[3] Adediran, G. O. and Nwosu, F. O. (1996). Some ffeundlich adsorption parameters of activated carbon. Journal of Chemical Society of Nigeria, 21 - 28.

[4] Ademiluyi, FT, Amadi S. A. and Amakama N. J. (2009). Adsorption and treatment of organic contaminants using activated carbon. Journal of Applied Science and Environmental Management, 13(3), 39-47).

[5] Ademoroti, C. M. A. (1996). Standard method for water and Effluent Analysis. Foludex, Press Ltd. Ibadan. $37-62$.

[6] APHA, C. E (2002). Method for the examination of water and wastewater. American Public Health Association, $5^{\text {th }}$ ed. USA. 230-241, 256.

[7] APHA, C. E (2002). Method for the examination of water and wastewater. American Public Health Association, $5^{\text {th }}$ ed. USA. 230-241, 256.

[8] Association of Official Analytic Chemist. Official Methods of analysis $13^{\text {th }}$ Edn. Association of Analytical Chemists. Washington D.C 1980, 176-2001.

[9] Association of Official Analytic Chemist. Official Methods of analysis $13^{\text {th }}$ Edn. Association of Analytical Chemists. Washington D.C 1980, 176-2001.

[10] Atkins, P and Paula, J. (2008). Atkin's physical chemistry. Oxford University Press, pp 916 - 917.

[11] Azbar, N. Y(2004 ). Comparative evaluation of a laboratory and full-scale treatment alternatives for the vegetable oil refining industry wastewater (VORW). Process Biochemsitry, 39 (7), 869-875.

[12] Castilla, M. C. (2004). Adsorption of organic molecules from aqueous solutions on carbon materials. Carbon, 42, 83 - 94.

[13] Chiang, Ho, Y. S. and C. C. (2001). Sorption Studies of Acid dye by Mixed Sorbents. Springer Science and Business Media B. V., Formerly Kluwer, 7 (2) 139 - 147.

[14] Dubinin, M.M and Radushkevich, L.V (1947). The equation of the characteristic curve of the activated charcoal. Proc. Acad.Sci. USSR. Phys. Chem. Sec., 55, 331-337.

[15] Dunnivant F.M., and E. Anders (2006). A Basic Introduction to Pollutant Fate and Transport, An Integrated approach with Chemistry, Modeling, Risk assessment and Environmental Legislation. Published by John Wiley \& Sons, Inc., Hoboken, New Jersey. Pp.4

[16] Faust, S.D. and Aly, O.M. (1987). Adsorption Process for Water Treatment, Butterworths publishers, Stoneham.

[17] Franz, M.; Arafat, H. A. and Pinto, N. G. (2000). Effect of chemical surface heterogeneity on the adsorption mechanism of dissolved aromatics on activated carbon. Carbon, 38 (13), 1807- 1819.

[18] Gajghate, D. G.; Saxena, E. R, and Rao, M. (1990). Kinetics of adsorption of lead by activated carbon from aqueous solution. Indian Journal of Environmental Health, 32, 369 -376

[19] Gupta, V. K., Srivastava, S. and Tyagi, R. (2000). Design parameters for the treatment of phenolic wastes by carbon columns (obtained from fertilizer waste materials). Water Resources, 34 (5), 1543 - 1550.

[20] Hamdaoui, Q. and Naffrechoux, E. (2007). Modeling of adsorption isotherms of phenol and chlorophenols unto granular activated carbon. Part 1. Two parameter models and equations allowing determination of thermodynamic parameters. Journal of Hazardous Substances, 147, 381 - 394. 
[21] Horsfall, M. Jnr and Spiff, A. I. (2005d). Sorption of lead, cadmium and zinc on sulfure - containing chemically modified wastes of fluted pumpkin (Telfiaria occidentalis Hook F.) J. Chemistry and Biodiversity., 2, 1 - 12.

[22] Kim, S. J., Shim, W. G., Kim, T. Y, Moon, H, Kim, Seung J., and Cho, S. Y. (2002). Adsorption equilibrium characteristic of 2, 4 dichlorophenoxyacetic acid and 2, 4 dinitrophenol on granular activated carbons. Korean Journal Chemical Engineering, 19 (6), 967-977.

[23] MacDonald, J. A. F. and Evans, M. J. B. (2002). Adsorption and enthalpy of phenol on BPL carbon. Carbon, 40, 703-707.

[24] MacDonald, R. J.; Tagauer, E. C. and Wandelt, K. R. (1996). Surface science: Principles and current applications. Berlin, New York: Springer.

[25] MacKay, G.; Ramprasad, G and Mowli, P. P. (1985). Equilibrium studies for the adsorption of dye stuffs from aqueous solutions by low cost materials, Water Air and soil pollutions, 20, $272-282$

[26] Maduagwu, U. A. (2008). The sorption kinetics of metal ions of copper (II) and lead (II) from aqueous solution using carbonized African Bread fruit (Treculia africana). Husk biomass; unpublished B.Sc. project work Nnamdi Azikiwe University, Awka.

[27] Shah, B.A, Shah, V. A and Patel, H.D (2011). Alkaline hydrothermal conversion of agricultural waste bagassefly ash into zeolite : Utilisation in dye removal from aqueous solution. International Journal of waste management, 7 (1/2), 192-208.

[28] Verla, A. W.; Nwosu, P. J. C.; Verla, E. N. (2008). Physicochemical Characteristics of produced water from crude oil processing and its public health implications. Tropical Journal of Biomedical and Allied Science Research, 2(1), 137- 140.

[29] Verla, A. W.; Verla, E. N. and Lukong, C. B. (2008). Characterisation of pet-ether extracts from seeds of Monodora myristica (Gaertn): Tropical Journal of Biomedical and Allied Science Research, 2 (1), 141 146.

[30] Vidic, R. D.; Chang, M. T. and Thurnau, R C. (1998). Kinetics of vapour-phase mercury uptake by virgin and sulphur-impregnated carbons. Journal of the Air and waste management Association, 48, 247 -255.

[31] Verla, A.W, M. Horsfall (Jnr), E.N Verla, A.I. Spiff, O.A. Ekpete (2012a). Some Aspect of Surface Chemistry of Activated Carbon Prepared Prepared from Fluted Pumpkin (Telfairia occidentalis Hook. F.) by Physical Activation. International Journal of Chemical Science and Technology, 2 (3), 224-230.

[32] Verla, A.W, M. Horsfall (Jnr), E.N Verla, A.I. Spiff, O.A. (2012b). Ekpete.Preparation and Characterization of Activated Carbon from Fluted Pumpkin (Telfairia occidentalis Hook. F). Seed Shell, Asian Journal of Natural and Applied Sciences, 1(3), 39-50.

[33] Verla, A.W (2013). Reducing biochemical oxygen demand ( BOD $_{5}$ ) and chemical oxygen demand (COD) removal from vegetable oil industrial effluents using activated carbon prepared from telfairia occidentalis Hook. . Phd. Thesis, University of Port Harcourt Choba , Nigeria.

Citation: Verla Andrew Wirnkor, "Removal of Biochemical and Chemical Oxygen Demands in Vegetable Oil Industry Effluents using Adsorbents from Fluted Pumpkin Mesocarp", International Journal of Advanced Research in Chemical Science, vol. 6, no. 11, p. 1-11, 2019. DOI: http://dx.doi.org/10.20431/23490403.0611001

Copyright: () 2019 Authors. This is an open-access article distributed under the terms of the Creative Commons Attribution License, which permits unrestricted use, distribution, and reproduction in any medium, provided the original author and source are credited. 